it could have benefited from further elaboration and exposition.

Part 1 summarises the arguments for personal autonomy, defined as 'acting on one's own reasons, not on those of other people'. The authors outline why this is valued as a good in its own right, only to be interfered in with significant moral justification. Paternalism is shown generally to act to undermine individual autonomy (although it can be justified e.g. for public health). Medicine is defined 'not as a science but an interpretive practice relying on clinical reasoning'. The patientdoctor consultation is rightly situated as the 'central act of medicine'. The way people make decisions is considered: not as isolated units but in dialogue with their significant others.

The best section is on Miranda Fricker's concept of epistemic injustice. Fricker has highlighted two types of injustice: testimonial and hermeneutical. Testimonial injustice refers to a speaker being awarded less credibility owing to prejudice on the listener's part, e.g. a woman speaking in a male-dominated boardroom. Psychiatric patients are particularly susceptible to this credibility deficit. The authors cite Elyn Saks's account of attending the accident and emergency department with a brain haemorrhage. When doctors heard of her history of schizophrenia, they stopped diagnostic investigations and sent her home. Hermeneutic injustice occurs when an individual/group does not have access to, or is not represented within, the shared generation of meaning. Here the injustice is often to the subject who questions the credibility of their own testimony. An example is a depressed new mother trying to make sense of her feelings without any knowledge of postnatal depression.

Part 2 addresses specific problems: mental health legislation, do-not-resuscitate orders, and assisted dying. These are condensed and well-written, but there is nothing new for anyone working clinically in these specialties.

Overall, this is a clear and concise introductory work useful for anyone interested in this area.

Lisa Conlan, Consultant Psychiatrist, South London and Maudsley National Health Service Foundation Trust; email: lisa.conlan@slam.nhs.uk

doi:10.1192/bjb.2017.18

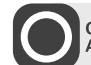

OPEN ACCESS

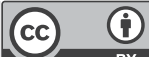

(c) The Author 2018. This is an Open Access article, distributed under the terms of the Creative Commons Attribution licence (http://creativecommons.org/ licenses/by/4.0/), which permits unrestricted re-use, distribution, and reproduction in any medium, provided the original work is properly cited.

\section{Still Down: \\ What to Do When Antidepressants Fail}

By Dean F. MacKinnon

John Hopkins University Press, 2016, E14, pb, 152 pp.

ISBN: 9781421421063

Still Down by Dean F. MacKinnon, a US-based psychiatrist, is a patient-centred guide written primarily for patients - and their families - seeking effective management for treatment-resistant depression.
The book begins with a revision of the symptoms of major depressive disorder and a summary of how treatment has developed to include a wide range of antidepressant medications that allow patients to be trialled on alternative treatments when any one agent is unsuccessful. The author explains treatment-resistant depression - where patients fail to respond to antidepressant therapy - using nine case studies that suggest reasons for treatment failures, starting with relatively straightforward cases and ending with more complex scenarios. Scenarios include patients who have been inadequately treated or misdiagnosed as well as patients who are 'treatment resistant.' Strategies, both biological and psychological, based on the author's own clinical experiences are suggested as ways to overcome antidepressant failure. These are summarised in a table towards the end of the publication.

MacKinnon presents cases concisely, in an engaging and conversational style. Each presentation ends with a summary of the key (general) clinical points and case notes which highlight diagnostic features specific to the patient's individual presentation.

The main strength of this work is its clarity of information. Easy-to-read prose, bullet-points and tables help break up the text in ways that aid comprehension. Explanation of medical jargon where used and the relative absence of jargon ensures suitability to the target audience. Limitations include its focus on treatments approved by the U.S. Food and Drug Administration, which may be less relevant in countries other than the USA. Furthermore, the book does not include novel evidence on pharmacological or psychological treatments. Irrespective of this, it remains a valuable commodity for healthcare professionals, offering a general revision of the topic and inspiring an individualised approach to managing patients.

In summary, this is a well-written and helpful resource for patients and relatives seeking to gain a better understanding of depression and its management.

Lena Jawad, ST5 in General Psychiatry, Birmingham and Solihull Mental Health NHS Foundation Trust, London, UK; email: lenajawad@doctors.org.uk

\section{doi:10.1192/bjb.2017.27}

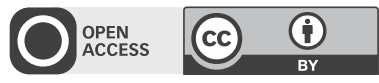

(c) The Author 2018. This is an Open Access article, distributed under the terms of the Creative Commons Attribution licence (http://creativecommons.org/ licenses/by/4.0/), which permits unrestricted re-use, distribution, and reproduc tion in any medium, provided the original work is properly cited.

\section{Mental Capacity Legislation: Principles and Practice.}

Edited by Rebecca Jacob, Michael Gunn and Anthony Holland RCPsych Publications 2017, £25, hb, 128 pp.

ISBN: 978-1909726000

The Mental Capacity Act (MCA) has now been in operation for 10 years, and MCA case law has proliferated over this time. Books on this subject still remain vital to continue to embed this statute in practice. This book is a reprint of the original publication in 2013. It is aimed at psychiatrists and other 
mental health professionals and aims to provide 'user-friendly' guidance for medico-legal dilemmas that require an understanding of the MCA (and where it juxtaposes with the MHA statute). It is a readable book of only six chapters and 128 pages, which should appeal to busy professionals.

All chapters contain salient advice. Probably the most apposite chapter is that on best interests, especially with important case law having emerged in this area in recent years since the book was published (and given a prescient statement regarding best interests assessments and the need to fully involve the person and people who know them well that psychiatrists 'have not been accustomed to this type of thinking', which this chapter readily addresses). The section on the role of the Court of Protection is enlightening. Useful advice around the practical challenges of applying the MCA in the clinical setting is elucidated in the final chapter analysing clinical ambiguities in the assessment of capacity.

The book could have been improved for the reader by having easy to read learning points at the end of each chapter, and by having an annexe with the relevant MCA sections cited in full. Also, because case law does evolve, having a section recommending various legal resources would be helpful to enable professionals to readily keep up to date, e.g. online legal search engines and access to free monthly legal newsletters. A table comparing enduring power of attorney and both types of lasting power of attorney would also be useful.

It is unclear as to why the book has been reprinted without being updated with the advances in MCA case law since 2013. Some of these advances have been seminal in nature, especially in the areas of consent to treatment, best interests, end-of-life care and Do Not Attempt Cardiopulmonary Resuscitation orders, and, importantly Deprivation of Liberty Safeguards (DoLS), namely the 'acid test' that emerged from the Supreme Court after a 'DoLS-athon' in the lower courts. However, it still covers many areas of the MCA well enough for clinical practice, and is indeed 'user-friendly'. It is a shame it wasn't updated, as it would undoubtedly then be an extremely useful book to have for clinical practice.

Martin Curtice is a Consultant in Old Age Psychiatry, Worcestershire Health and Care NHS Trust, UK; email: mjrc68@doctors.org.uk

doi:10.1192/bjb.2017.31
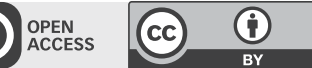

(c) The Author 2018. This is an Open Access article, distributed under the terms of the Creative Commons Attribution licence (http://creativecommons.org/ licenses/by/4.0/), which permits unrestricted re-use, distribution, and reproduction in any medium, provided the original work is properly cited.

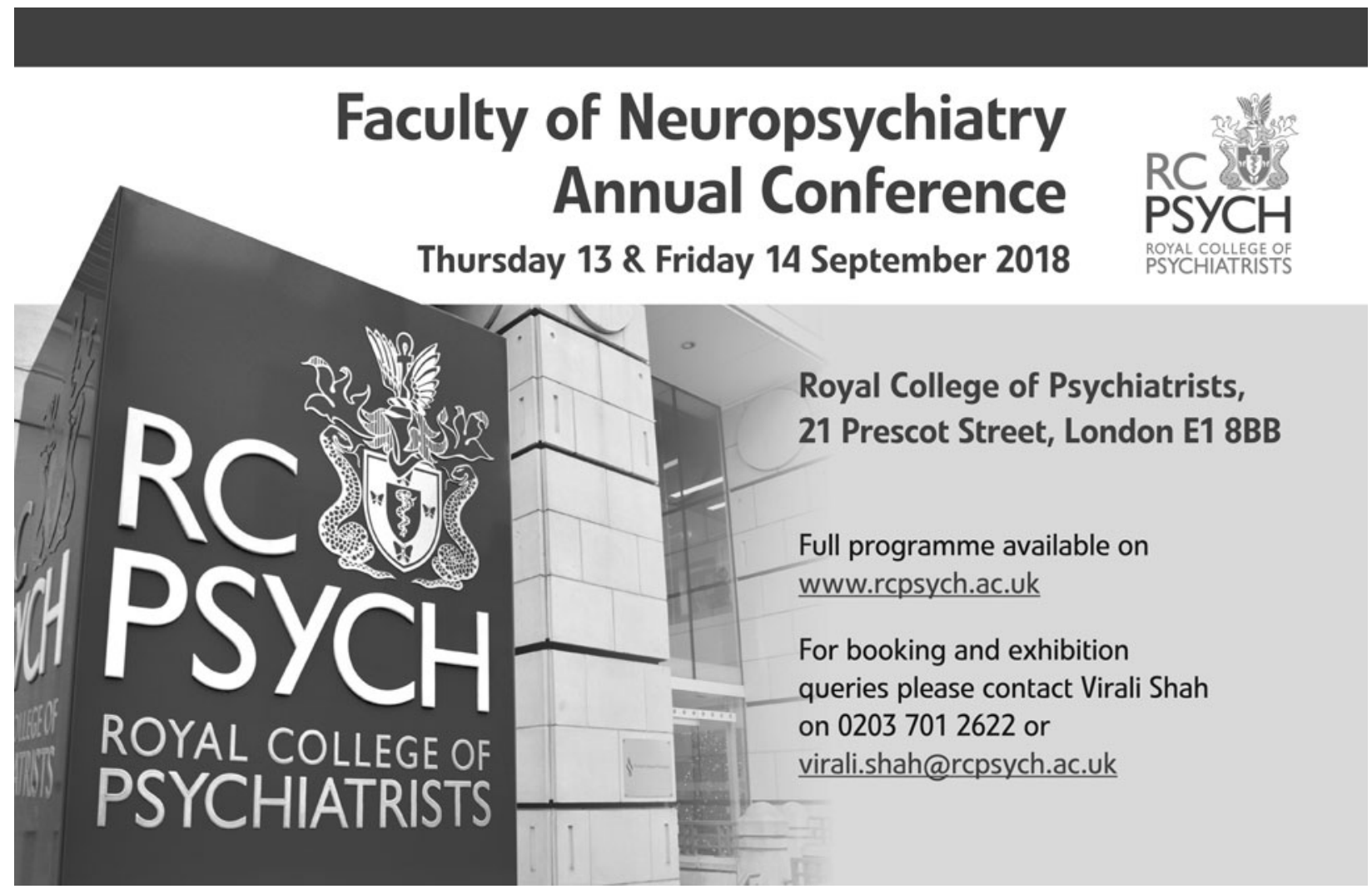

